\title{
Mahanama Bridge, Matara: A suicide Hotspot in Southern Sri Lanka
}

\author{
Vajira Dharmawardene
}

Key words: Sri Lanka, Suicide Prevention, Bridges, Hotspots

An adage circulated among doctors at District General Hospital Matara says the psychiatrist attached to hospital should be positioned at the nearby Mahanama Bridge.

Over the last few years this iconic bridge that spans over Nilwala River and runs through Matara town has attained notoriety as a popular place for jumping to river for suicide and could be described as a suicide hotspot. The bridge partially destroyed by the tsunami, was reconstructed to present state in 2007 and at present is 116 meters in length, 29.5 meters wide and has Colombo -Wellawaya A2 main road over it.

A 'suicide hotspot' is a specific, usually accessible public site that is frequently used as a location for suicide. Though there is no standard definition on a suicide hot spot, most agree that more than one suicide at a particular location suggests that the site has appeal for suicidal individuals and provides means or opportunity for suicide. ${ }^{1}$ The most common types of suicide hotspot are bridges, tall buildings and cliffs. Suicides at these sites often receive wide media coverage that may increase the risk of "copy cat" attempts. ${ }^{2}$

Over the last few years the jumping to river at Mahanama Bridge has been a regular occurrence. Police data from Jan 2016 to 31 August 2017 indicate 7 ( 6 male +1 female) confirmed deaths by suicide at this site. It amounts to approximately $5 \%$ deaths by suicide in Matara district. ${ }^{3}$ This rate is comparable to those reported for other suicide hotspots globally. ${ }^{1}$

Like ingestion of Kaneru (Oleander) seeds and pesticide ingestion have been methods of suicide in mostly the dry zone of the country, jumping to river appears prominently in Matara compared to other districts. ${ }^{4}$ The pattern is in accordance with easy access to a particular method as a key determinant of ultimate death in people who attempt self harm. Increasing availability of toxic agrochemical pesticides with the introduction of green revolution technologies in agriculture coincides with peak rise in suicide in Sri Lanka and Oleander seed use in dry zone of the country where the plant is widely distributed are examples of this association. Oleander seed ingestion gaining popularity as a method was probably spurred by wide media publicity given. ${ }^{5}$

Consultant Psychiatrist, District General Hospital, Matara

https://orcid.org/0000-0003-4794-4749
It is plausible that jumping to river at Matara Bridge have also been influenced by media reporting; given the wide coverage the incidences had received. The temporal pattern of suicide by jumping at Mahanama Bridge indicates temporal increase, close clustering; an evidence of contagion nature of this method. ${ }^{3}$

Humorous suggestion that a psychiatrist should man the bridge underlines the belief that psychiatrists can prevent suicide. Evidence for this has not been promising. Relationship between Mental illness and suicide is complex and studies on individuals who have survived self harm in Sri Lanka prominently indicate low prevalence of mental illness. ${ }^{6}$ Apart from lithium use in mood disorders and clozapine for schizophrenia, the evidence for psychiatric interventions in preventing deaths by suicide is limited. ${ }^{7,8}$

Evidence supporting effective preventing interventions for suicide comes from universal preventive strategies targeting whole populations compared to treating individuals. ${ }^{9}$ Sri Lanka provides a classic example of suicide prevention by means restriction by banning toxic pesticides. ${ }^{10}$ Sri Lanka's had its highest suicide rate in year 1995 at 45/10000 with total deaths at 8,500. By 2005, the number had halved and in 2016, according to data from Police department it was $3,025 .^{4}$

Installation of barriers as a method of means restriction has been consistently shown to be an effective way of preventing suicide by jumping from bridges. ${ }^{1}$ Secured bridgeheads and inbound angle barriers seemed to enhance the effectiveness of the measure. These make the act difficult to perform.

Means restriction at bridges sometimes leads to protest by local authorities citing aesthetic reasons and arguing that site substitution occur. The research evidence has shown that restriction at one location does not lead to site substitution by suicidal individuals to seek alternative locations. Preventive effect could be clearly demonstrated upon follow up. At Grafton Bridge in Auckland, New Zealand, removal of initial barriers following protest lead to a reemergence of earlier pattern of suicide jumping, which reversed again following installation of barriers, this time made of more aesthetically pleasing curved glass. ${ }^{11}$

Suicide prevention needs to be evidence based. Anyone to claim credit for the reduction of suicide in this country 
should first be able to show that they have advocated strongly and collectively for the known effective measures. ${ }^{12}$ Resources, which is always limited, needs to be utilized for most effective interventions. Some well intended interventions like school based programmes have weak evidence base and the often the study endpoint has been outcomes like suicidal ideation, not suicide.

Application of best evidence to practice clearly calls for intervention at Mahanama Bridge, Matara by installation of barriers. The responsibility to act belongs to authorities responsible for bridges and government agencies accountable for suicide prevention. Negligence of a well-established intervention could lead to liability.

Preventing media form glamorizing these events could be another intervention. Though a Suicide sensitive media hand book for Sri Lanka was prepared in $2003^{13}$ these guidelines are rarely adhered to. Increasing number of media organizations channels competing for viewer attention doesn't help either.

It is revitalizing to note that some journalists have recognized the culpability of media. How such recognition could be upgraded to enduring change in reporting practices need to be actively explored.

\section{References}

1. Cox GR, Owens C, Robinson J, Nicholas A, et al: Interventions to reduce suicides at suicide hotspots: a systematic review. BMC Public Health 2013, 13:214

2. Hawton K, Williams K. Influences of the media on suicide: Researchers, policy makers, and media personnel need to collaborate on guidelines. BMJ : British Medical Journal 2002; 325(7377):1374-1375. Stack S.Media coverage as a risk factor in suicide. Journal of Epidemiology \& Community Health 2003;57:238-240.

3. Section of Statistics, Office of the Superintendent of Police, Matara.(accessed on 01/09/2017)

4. https://www.police.lk/images/others/crime_ trends/2016/mode_of_suicides.pdf
5. Saravanapavananthan N, Ganeshamoorthy J. Yellow oleander poisoning - a study of 170 cases. Forensic Science International 1988; 36, 247- 250.

6. Dharmawardene V, Perera EMSS. Non-Fatal Selfharm in Anuradhapura: Recent life events and methods. Sri Lanka College of Psychiatrists annual academic aessions, Colombo 2015(Abstract)

7. Cipriani A, Hawton K, Stockton S, Geddes JR. Lithium in the prevention of suicide in mood disorders: updated systematic review and meta-analysis. BMJ 2013; 346: f3646.

8. Asenjo Lobos $\mathrm{C}$, Komossa $\mathrm{K}$, Rummel-Kluge $\mathrm{C}$, et al. Clozapine versus other atypical antipsychotics for schizophrenia. Cochrane Database Syst Rev 2010; 11: CD006633.

9. Yip P, Caine E, Yousuf S, Chang S-S, Wu K, Chen Y-Y: Means restriction for suicide prevention. Lancet 2012, 379:2393-2399.

10. Gunnell D, Knipe D, Chang SS, et al. Prevention of suicide with regulations aimed at restricting access to highly hazardous pesticides: a systematic review of the international evidence. Lancet Glob Health. 2017 Oct; 5(10):e1026-e1037.

11. Beautrais AL, Gibb SJ, Fergusson DM, Horwood LJ, Larkin GL: Removing bridge barriers stimulates suicides: An unfortunate natural experiment. Aust NZ J Psychiat 2009, 43(6):495-497.

12. Samarasinghe D. Falling Suicide Rates in Sri Lanka: lessons and cautions.SL J Psychiatry 2013; 4 (2):1-3

13. Center for Policy Alternatives Sri Lanka and PressWise Trust (UK) Suicide Sensitive Journalism Hand book (2003) 